\title{
"PEZINHO DE JATOBÁ" \\ Um projeto resultante do bem sucedido binômio Meio Ambiente X Comunicação
}

\author{
Lisbeth Oliveira*
}

\section{Resumo}

É um projeto de extensão que vem sendo desenvolvido pela Faculdade de Comunicação e Biblioteconomia em conjunto com professores e alunos de outras Faculdades da UFG. A interdisciplinaridade vem se mostrando uma saída rica para o avanço em direção à discussão mais profícua dos problemas ambientais, que devem ser tratados no plano da vida pública, mediante relações transparentes que permitam o controle democrático entre os vários atores sociais que interferem no ambiente. O jornalismo não pode ficar alheio à problemática ambiental. Nesse sentido, tem atuado no projeto de maneira decisiva, buscando dar visibilidade e interligando a Universidade com a comunidade carente do entorno do Campus II da UFG, em atividades quinzenais, num exercício de jornalismo comprometido com a contextualização dos fatos. O projeto tem priorizado a educação ambiental - envolvendo as crianças do Setor Shangri-lá, onde se localiza extensa área verde municipal - por acreditar que ela capacita o pleno exercício da cidadania. $O$ direito à informação e o acesso às tecnologias capazes de viabilizar o desenvolvimento sustentável constituem, assim, pilares desse processo de formação de uma nova consciência em nível planetário, criando bases para a compreensão holística da realidade.

Palavras-chave: meio ambiente e comunicação - educação ambiental-jornalismo ambiental.

* Mestre em Teoria da Imagem/Fotografia Documental pela Universidade de Viena, Áustria. Pesquisadora e Professora da Faculdade de Comunicação e Biblioteconomia da Universidade Federal de Goiás.

Comun. Inf., v. 6, n. 2, p.87-97, jul./dez. 2003 


\section{Por que Pezinho de Jatobá? - um breve histórico:}

Era um dia seco e de ventania, no mês de julho de 2001, quando Noemi Furlanetto, moradora do Setor Shangri-lá percebeu fogo na direção da mata e foi conferir. O fogo - depois se constataria, fora mesmo "colocado" - e já destruíra todo um quarteirão verde, perto da reserva municipal, atingindo o jatobá imenso e frondoso da Rua Xavante, cuja única família moradora do local estava viajando. Noemi tentou conter o fogo. Em vão. O calor e a fumaça a impediram. Chamou os bombeiros que, após algumas investidas, deixaram o jatobá fumegando, sob a alegação de que agora o fogo já não representava perigo para "nenhuma moradia". Quatro dias se passaram e o jatobá fumegava.

Passado o trágico episódio, a árvore milagrosamente ainda estava de pé, presa a uma fina casca ao redor do caule. Juntamo-nos na tentativa de salvá-la. Experimentamos fazer-lhe uma prótese de cimento, ferro e brita. Funcionou e a árvore floresceu, voltando a embelezar a paisagem com sua copa verdinha. Com as crianças do bairro, fizemos fotos sob aquela sombra imensa. Mas fortes ventanias ainda estavam por vir. Numa quarta-feira, finalzinho da tarde de $12 \mathrm{de}$ setembro de 2001, ouvimos o estrondo, seguido de um chiado triste e demorado. $\mathrm{O}$ caule remendado cedera à força do vento $\mathrm{e}$ ao peso dos galhos verdes. Tombou expondo o remendo feito e deixando os ferros à mostra. Choramos de tristeza. $\mathrm{O}$ projeto, iniciado no início daquele ano, recebeu então o nome de Pezinho de Jatobá, numa homenagem a essa espécie ainda freqüente na Reserva Municipal Shangri-lá e arredores. Desde então nossa meta maior tem sido a Educação Ambiental. Buscamos, em primeiro lugar e de maneiras diversas, envolver as crianças, pois sabemos que com elas chegaremos aos pais e adultos da comunidade. Acreditamos que a pessoa inserida nesse processo tende a mudar o seu modo de ver o mundo e relacionar-se com ele. Tende a agregar novos elementos à sua cultura.

Nossa metodologia adota o trabalho interdisciplinar, pois estamos convictos de que as várias áreas do conhecimento em sintonia atendem à demanda da Educação Ambiental.

Luís Fernando Angerami Ramos ${ }^{1}$, quando busca analisar como foi a cobertura dada pela imprensa à Conferência Mundial sobre Meio Ambiente no Rio de Janeiro, em 1992, afirma que a busca da interdisciplinaridade na Ciência Ambiental tornou-se fundamental,

Comun. Inf., v. 6, n. 2, p.87-97, jul./dez. 2003 
"uma vez que os modelos tradicionais de análise compartimentalizada em áreas distintas do conhecimento se mostraram insuficientes para a abordagem dos problemas complexos que envolvem o ambiente"

Para esse autor, quando a sociedade interfere e colabora para que os meios cumpram sua função original e específica, ela está promovendo a necessária integração para que possam exercer realmente uma função comunicadora. Isso requer esforços sociais permanentes, mobilização política da sociedade para a solução de seus problemas.

Dessa forma é que as classes populares vêm criando seus próprios canais de expressão e também conquistando espaço nos canais tradicionais de informação para divulgar suas mensagens.

\section{Desafios de uma Educação Ambiental ${ }^{2}$}

Os problemas socioambientais decorrentes do processo acelerado de "urbanização" nas grandes cidades alcança dimensões preocupantes. Goiânia não é uma exceção à regra. Os últimos governos municipais relegaram a segundo plano questões prementes de proteção ao meio ambiente, principalmente na periferia da cidade, como é o caso dos bairros circunvizinhos ao Campus II da UFG, um deles, o Setor Shangri-lá, objeto de nossa reflexão.

Hoje a problemática ambiental, traduzida no tratamento que se dá ao lixo, no planejamento urbano, na poluição da água, no desaparecimento rápido de nossas áreas verdes, afeta a todos nós, tanto moradores das chamadas "áreas nobres" quanto dos setores "periféricos e carentes" da cidade.

O projeto Pezinho de Jatobá pretende ser uma contribuição no processo "lento", mas necessário de educação ambiental da população, dando enfoque àquele habitante de bairros de baixa renda, periféricos e carentes de assistência em todos os níveis.

O Shangri-lá é um setor que já existe há quase 20 anos (Lei Municipal $\mathrm{n}^{\circ} .6806 / 89$ e 6967/91) e possuidor de uma área pública municipal de $86.757,27 \mathrm{~m} 2$, reservada (pelo menos no mapa de orientação da cidade e respaldada pela Lei Municipal 7.777 de 23.4.1998) à preservação ambiental.

De fato, trata-se "ainda" de uma área verde que abriga jatobás frondosos, angicos, macacos, juruvas, pica-paus e várias outras espécies vegetais e animais. O descaso dos órgãos públicos responsáveis,

Comun. Inf., v. 6, n. 2, p.87-97, jul./dez. 2003 
contudo, é tamanho, que não se vê nem ao menos uma placa de sinalização informando a existência da área como tal.

Dessa forma, tem sido freqüente a extração ilegal de madeira, as queimadas indiscriminadas, principalmente na época seca, o roubo de bromélias e orquídeas ali existentes, a utilização da área para abrigo de marginais e alcoólatras, etc. A população do bairro tende a, por um lado, "temer" essa área, vendo-a como sinônimo de "perigo"; por outro lado, "usá-la" de um jeito ou de outro para extrair dela algum tipo de "lucro".

Dessa forma, entendemos a Educação Ambiental como ferramenta imprescindível para transformar essa realidade, contribuindo para a mudança de valores inculcados por décadas na nossa sociedade, valores estes que sempre vêem o homem como o centro do universo, reinando sobre as demais espécies. A partir daí, todo e qualquer ato do homem se justifica.

O projeto enfatiza o papel do Jornalista como figura importante no desempenho, por exemplo, de funções de assessoria de imprensa de órgãos públicos e instituições, visando a aplicação dos princípios bási$\cos$ da educação ambiental e servindo de porta-voz da comunidade junto a instâncias de decisão públicas e privadas. Estabelece também a participação de integrantes de outras áreas do conhecimento, por entender que a interdisciplinaridade enriquece e pode se traduzir num trabalho de resultados concretos e eficientes.

\section{Das motivações}

O que nos move, em primeiro lugar, a buscar a continuidade deste projeto é a urgência que o problema requer. Não se pode esperar mais que as autoridades responsáveis ajam, pois na prática temos visto que ações públicas são morosas e inversamente proporcionais, em termos de tempo, à velocidade com que o homem destrói, por ignorância ou não, o meio ambiente e a si próprio.

Tal atitude tem raízes profundas em nossa sociedade, que comumente confunde meio ambiente com fauna e flora. Assim, o homem não se percebe como parte do meio ambiente. Os meios de comunicação, nesse contexto, têm reforçado essa forma de pensamento e raramente percebem meio ambiente como algo que começa dentro de cada um de nós, atingindo tudo o que nos cerca e as relações que estabelecemos com o universo.

Comun. Inf., v. 6, n. 2, p.87-97, jul./dez. 2003 
Um projeto de Educação Ambiental, de natureza interdisciplinar, tem papel fundamental no processo de reversão dessa triste realidade. O jornalista, como profissional da comunicação, por sua vez, pode desempenhar papel de suma importância, seja prestando uma assessoria de imprensa séria, seja agindo como formador de opinião e elemento de conscientização dessas camadas da população. Isso depende, é claro, do desempenho pessoal do comunicador e de sua equipe interdisciplinar.

Certamente, como bem constatou, em 1995, Washington Novaes,

\begin{abstract}
"a questão ambiental é ameaçadora para os jornalistas na medida em que os jornalistas têm uma vida pessoal muito pouco adequada em termos ambientais. O jornalista, em geral, bebe muito, fuma muito, leva uma vida extremamente competitiva, apressada, estressante, onde a disputa pelo poder está sempre muito presente dentro e fora do trabalho, mora em cidades com problemas ambientais gigantescos, todas essas coisas. Ele vai ter que se perguntar um pouco sobre a sua vida" 3 .
\end{abstract}

$\mathrm{Na}$ atual situação, como o meio ambiente ainda não tem um lugar definido ou estável nas páginas da imprensa escrita, por exemplo, os temas ambientais que nos afligem precisam conquistar seu espaço e, mais, serem tratados de forma mais abrangente, resgatando...
“(...) o sentido holístico, o caráter multidisciplinar que permeia todas as áreas do conhecimento, e nos induz a uma leitura da realidade onde tudo está conectado, interligado, relaciona- do" 4 .

Para isso é necessário não só jornalistas engajados nessa luta, como populações que façam dos meios de comunicação porta-vozes de suas reivindicações, aliás, uma função que deveria nortear os meios de comunicação social.

Este projeto se justifica também na proporção em que venha servir como veículo prático do exercício profissional daqueles nele envolvidos, sejam estudantes em formação nas diversas áreas do conhecimento, sejam profissionais da Comunicação e outras áreas afins.

Comun. Inf., v. 6, n. 2, p.87-97, jul./dez. 2003 


\title{
O binômio comunicação - meio ambiente
}

No final do século XX, o binômio meio ambiente $\mathrm{x}$ comunicação adquire importância fundamental. Por um lado, pela amplitude dos problemas ecológicos; por outro, pelas possibilidades oferecidas pelas modernas tecnologias e disponibilidade dos meios. Essa relação se dá no plano político, já que os problemas ecológicos afetam a todos devido à sua distribuição e alcance globais, ou seja, um fato local pode alcançar transcendência universal, pela sistemática da própria natureza:

\begin{abstract}
“...os problemas ecológicos devem ser tratados no plano da vida pública, através de relações transparentes que permitam o controle democrático entre os vários atores sociais que interferem no ambiente (sociedade civil, órgãos públicos, grupos econômicos, comunidade científica, responsáveis dos meios de comunicação). Neste plano, os meios de comunicação social desempenham um papel específico por terem sido criados e implantados pela sociedade para circular informações, que, por sua natureza, se destinam a todas as pessoas de uma comunidade, nação, região, continente e até do planeta" 5
\end{abstract}

A relevância dessas questões coloca hoje o desafio principal que, segundo Wagner Costa Ribeiro, motiva a compreensão da ordem ambiental internacional e

\footnotetext{
"surge da necessidade de estabelecer uma medida que permita a reprodução da vida no planeta, a vida em seu sentido plural, fruto do que cada agrupamento humano construiu ao longo de sua existência. A expressão da moda que canaliza essa discussão é o "desenvolvimento sustentável" ${ }^{6}$
}

Aquela função dos meios de comunicação, de veicular dados, sons e imagens, permitindo que haja comunicação.entre pessoas e grupos sociais, permitindo a circulação de mensagens, precisa ser resgatada. Esse papel específico dos meios de comunicação, o fato de terem sido criados e implantados pela sociedade para circular informações, numa sociedade consciente esses meios deixam de ser apenas meios, para se transformarem em verdadeiros canais, à medida que servem à autoexpressão da sociedade, colocando-se efetivamente a serviço das populações com quais atuam.

Comun. Inf., v. 6, n. 2, p.87-97, jul./dez. 2003 
Apesar de não compartilharmos da opinião simplista de que a formação da consciência ambiental está ligada à freqüência com que determinado conteúdo ou opinião aparece nos Meios de Comunicação, é inegável o efeito que fatos ambientais têm quando noticiados por esses Meios, seja formando opinião, impulsionando movimentos sociais, moldando valores, interferindo na ação política ou ainda ditando padrões de comportamento sociais e culturais.

Assim, constata Luís Fernando A. Ramos ${ }^{7}$,

“... é com grande influência dos meios de comunicação que a humanidade, hoje, toma contato com os problemas ambientais e procura rediscutir os seus modelos de desenvolvimento e sua atuação no meio ambiente".

Isso vem ocorrendo, nas últimas décadas, em diversas situações, como na Conferência da ONU sobre Meio Ambiente e Desenvolvimento (1992), quando seus representantes signatários recomendaram a criação de esquemas inovadores que subsidiassem o acesso à informação, sempre que existissem impedimentos econômicos ou de outro tipo, principalmente nos países em desenvolvimento. Tal medida foi justificada pelo fato de que, em muitos países, a informação não é gerenciada adequadamente por falta de recursos financeiros, pessoal treinado, pelo desconinecimento de seu valor e outros problemas.

Durante a realização da Rio +10 , em 2002, na cidade de Joanesburgo, na África do Sul, e nas três edições do Fórum Social Mundial $(2000,2001,2002)$ realizadas em Porto Alegre (RS), bem como em publicações especializadas, a questão ambiental encontra-se no foco central, sendo colocada como necessária discussão, apontando para a grande questão da humanidade hoje, que é reconhecer que o planeta é finito. Seus recursos não são infindáveis e é urgente adotar padrões de produção e consumo sustentáveis, que não consumam mais recursos do que a biosfera terrestre é capaz de repor.

Outro aspecto no mundo de hoje bastante recorrente é a questão da imagem das grandes empresas, a cada dia mais preocupadas em apresentarem-se à opinião pública como "ecologicamente corretas". Buscando uma excelência ambiental para obter selos verdes do tipo ISO 14001 e evitando com isso também as barreiras comerciais a seus produtos no exterior, investem significantes valores em marketing e publicidade.

Comun. Inf., v. 6, n. 2, p.87-97, jul./dez. 2003 
Assim, é inegável a participação da comunicação no processo de discussão dos problemas ambientais como forma não só de fornecer subsídios para a elaboração de programas de educação ambiental, relevantes, sim, na conscientização dos problemas do meio ambiente, mas principalmente estimulando as comunidades a implantar e exigir um padrão de desenvolvimento com equilíbrio ambiental suficiente para se atingir uma efetiva melhoria na qualidade de vida.

\section{Os desafios de um Jornalismo Ambiental}

Foi na década de 1960, no bojo de uma política universal pacifista e de uma filosofia anti-violência que as causas ambientais se tornaram interesse dos meios de comunicação. O movimento ambientalista lutava por causas comuns à sobrevivência de todos os seres humanos e logo se tornaria uma apetitosa fonte de notícias. Protestos, manifestações, festivais de música etc começaram a aparecer com maior freqüência na imprensa mundial, principalmente depois da Conferência da ONU de Estocolmo (1972), quando a humanidade tomou conhecimento do buraco da camada de ozônio e seus prováveis impactos no equilíbrio climático do planeta.

Atualmente, é crescente o interesse dos profissionais de imprensa pelo chamado "Jornalismo Ambiental". Mesmo sem a existência de formação específica para o profissional que se interesse por essa área no Brasil, são muitos aqueles que vêm se dedicando a um tratamento mais cuidadoso das questões ambientais, até mesmo mediante uma formação autodidata:

"Idealistas e apaixonados, os profissionais de imprensa que se sentem atraídos por esse filão de notícias buscam espaço muitas vezes em jornais e revistas alternativos, fora da grande mídia. Reunidos na Eco Mídias - Associação Brasileira das Mídias Ambientais -, esse segmento apresenta, entre outras publicações, Eco-21, Ecologia \& Desenvolvimento, Gerenciamento Ambiental, Folha do Meio Ambiente, Meio Ambiente Industrial, Saneamento Ambiental e Terramérica, cujas tiragens somadas atingem aproximadamente 1,5 milhão de exemplares mensais. Os jornalistas ambientais vêm descobrindo novas formas de articulação fora das redações, como a Federação Internacional dos Jornalistas Ambientais... e a Rede Brasileira de Jornalismo Ambiental..."

Comun. Inf., v. 6, n. 2, p.87-97, jul./dez. 2003 
É presente o desafio que se impõe ao exercício profissional do jornalismo ambiental. Novas formas de articulação vêm sendo conquistadas fora das redações e projetos comunitários, como o Pezinho de Jatobá, se somam a inúmeros outros exemplos de laboratórios vivos existentes por todo o país, possíveis de contribuir para a formação de futuros e atuantes profissionais da comunicação. Profissionais estes que consigam dedicar um tratamento transversal a questões tão prementes, "fortalecendo a construção de uma cidadania ecológica planetária", como tão bem formulou Fritjot Capra:

"A alfabetização ecológica deve se tornar um requisito essencial para políticos, empresários e profissionais de todos os ramos, e deveria ser uma preocupação central da educação em todos os níveis - do ensino fundamental e médio até as universidades e os cursos de educação continuada e treinamento de profissionais" 9

Segundo Capra, a alfabetização ecológica é muito mais que educação ambiental, exatamente por estar fundamentada no pensamento sistêmico:

“... o pensamento sistêmico é o núcleo intelectual da alfabetização ecológica, o arcabouço conceitual que nos permite integrar seus vários componentes. À medida que nosso século se desdobra, a sobrevivência da Humanidade dependerá de nossa alfabetização ecológica: nossa capacidade de compreender os princípios básicos da ecologia e viver de acordo com eles. Este é um empreendimento que transcende todas as diferenças de raça, cultura ou classe social. A Terra é nosso lar comum, e criar um mundo sustentável para nossas crianças e para as futuras gerações é uma tarefa para todos nós"10.

É nesta direção que queremos seguir, em busca do pensamento sistêmico, multiplicando uma iniciativa que não pretende se circunscrever nos limites da Universidade, mas que ensine esse saber ecológico para uma vida sustentável. Nesse processo, acreditamos que todos nós, comunicadores ou não, temos um papel importante na educação do século XXI.

Comun. Inf., v. 6, n. 2, p.87-97, jul./dez. 2003 


\section{Abstract}

"Pezinho de Jatobá" is a project developed by the Faculdade of Comunication together with professors of other Faculdades of the UFG. The interdisciplinary actuation is a rich solution for the useful discussion of environments problems which have to be treated in the public and social life through a transparent and democratic discussion. Journalism cannot be distant of the environment problems. In this sense the projet conect the university with the needy comunity around the Campus II of the UFG. The activities in periods of fifteen days, shows a journalism compromised with the context of the facts. The project's priority is environment education with children of the neighborhood Shangri-lá of Goiânia, where is situated a environment area. The right and the access of information, and education constitute the pillars of an sustainable development and an holistic understanding of reality.

Key words: comunication and environment; environment education; environment journalism.

\section{Notas}

1. RAMOS, L. F. A. Meio Ambiente e Meios de Comunicação. São Paulo: Annablume/FAPESP, 1996.

2. Utilizamos o termo Educação Ambiental com base nos subsídios técnicos elaborados pela Comissão Interministerial para a preparação da Conferência das Nações Unidas sobre Meio Ambiente e Desenvolvimento (versão julho/1991), que apresentou as bases conceituais da Educação Ambiental: "A educação ambiental se caracteriza por incorporar as dimensões socioeconômica, política, cultural e histórica, não podendo basear-se em pautas rígidas e de aplicação universal, devendo considerar as condições e estágio de cada país, região e comunidade sob uma perspectiva histórica. Assim sendo, a educação ambiental deve permitir a compreensão da natureza complexa do meio ambiente e interpretar a interdependência entre os diversos elementos que conformam o ambiente, com vistas a utilizar racionalmente os recursos do meio na satisfação material e espiritual da sociedade no presente e no futuro.

Para fazê-lo a educação ambiental deve capacitar ao pleno exercício da cidadania, através da formação de uma base conceitual abrangente, técnica e culturalmente capaz de permitir a superação dos obstáculos à utilização sustentada do meio. $\mathrm{O}$ direito à informação e o acesso às tecnologias capazes de viabilizar o desenvolvimento sustentável constituem, assim, um dos pilares deste processo de formação de uma nova consciência em nível planetário, sem perder a ótica local, regional e nacional. O desafio da educação, neste particular, é o de criar as bases para a compreensão holística da realidade. (Educação Ambiental no Brasil, p. 63. Citação feita por Genebaldo Freire Dias em "Educação Ambiental, princípios e práticas”, Editora Gaia, S. Paulo, 1998, p. 27).

Comun. Inf., v. 6, n. 2, p.87-97, jul./dez. 2003 
3. Relato do Encontro Imprensa e Meio Ambiente. São Paulo: Fundação SOS Mata Atlântica/ Fundação Konrad Adenauer, 1996, p. 27.

4. TRIGUEIRO, A. "Meio Ambiente na Idade Mídia", in Meio Ambiente no Século 21. Rio de Janeiro: Sextante, 2003, págs. 77-78.

5. VIEZZER, M. L.; OMAR, O. (Org.). Manual latino-americano de educação ambiental. S. Paulo: Gaia, 1995. p. 77.

6. RIBEIRO, W. C. Aordem ambiental internacional. S. Paulo: Contexto, 2001.p. 13.

7. RAMOS, L. F. A. Obra citada, p. 14.

8. TRIGUEIRO, A. "Meio Ambiente na Idade Mídia", in Meio Ambiente no Século 21, Ed. Rio de Janeiro: Sextante, 2003. p. 84-85.

9. CAPRA, F. Alfabetização ecológica: o desafio para a educação do século 21, in meio ambiente no século 21. Rio de Janeiro: Sextante, 2003. p. 25.

10. CAPRA, F. Obra citada, p. 33.

\section{Referências}

RAMOS, L. F. A. Meio ambiente e meios de comunicação. S. Paulo: Annablume, 1996.

HAAN, G. Umweltbewußtsein und massenmedien: perspektiven ökologischer kommunikatio. Berlin: Akademie Verlag, 1995.

REIGOTA, M. Meio ambiente e representação social. 3. ed. S. Paulo: Cortez, 1998.

FREIRE, R. A farsa ecológica. Rio de Janeiro: Ed. Guanabara Koogan S/A, 1992. DIAS, G. F. Educação ambiental, princípios e práticas. S. Paulo: Ed. Gaia, 1998 LIMA, E. P. Econautas, ecologia e jornalismo literário avançado. Canoas/RS: Editora da ULBRA, 1996.

RODRIGUES, A. M. Produção e consumo do e no espaço: problemática ambiental urbana. S. Paulo: Hucitec, 1998.

SOUZA, N. M. Educação ambiental: dilemas da prática contemporânea. Rio de Janeiro: Thex Editora, 2000.

TRAJBER, R.; MANZOCHI, L. H. Avaliando a educação ambiental no Brasil: materiais impressos. S. Paulo: Gaia, 1996.

VIEZZER, M. L.; OVALLES, O. Manual latino-americano de educ-ação ambiental. S. Paulo: Gaia, 1995.

COLBORN, T. D. D.; PETERSON, J. M. O futuro roubado. Porto Ảlegre: L\&PM, 1997.

RIBEIRO, W. C. A ordem ambiental internacional. S. Paulo: Contexto, 2001.

TRIGUEIRO, A. (Org.). Meio ambiente no século 21: 21 especialistas falam da questão ambiental nas suas áreas de conhecimento. Rio de Janeiro: Sextante, 2003.

Comun. Inf., v. 6, n. 2, p.87-97, jul./dez. 2003 